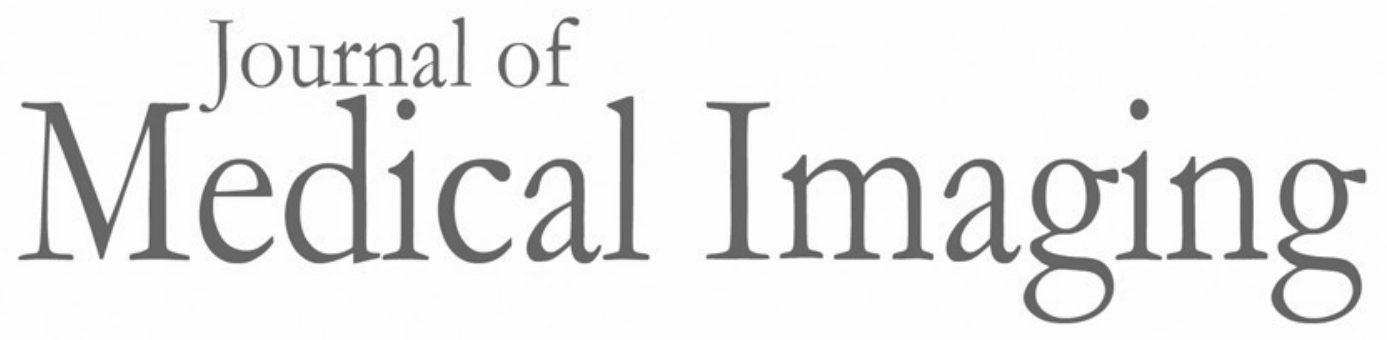

Medicallmaging.SPIEDigitalLibrary.org

\title{
Segmentation and classification of consumer-grade and dermoscopic skin cancer images using hybrid textural analysis system (Erratum)
}

\author{
Afsah Saleem \\ Naeem Bhatti \\ Aqueel Ashraf \\ Muhammad Zia \\ Hasan Mahmood
}




\section{Segmentation and classification of consumer-grade and dermoscopic skin cancer images using hybrid textural analysis system (Erratum)}

Afsah Saleem, Naeem Bhatti, Aqueel Ashraf, Muhammad Zia, and Hasan Mahmood Quaid-i-Azam University, Department of Electronics, Islamabad, Pakistan

[DOI: 10.1117/1.JMI.6.3.039802]

This article [J. Med. Imag. 6(3), 034501 (2019), doi: 10.1117/1 .JMI.6.3.034501] was originally published online on 6 August 2019 with an error in the spelling of an author's surname. The correct spelling is Mahmood.
This article was corrected online on 20 August 2019. It appears correctly in print. 